\title{
BMJ Open Retrospective cross-sectional analysis of the changes in marijuana use in the USA, 2005-2018
}

\author{
William Mitchell (D , ${ }^{1}$ Roma Bhatia, ${ }^{2}$ Nazlee Zebardast ${ }^{3,4}$
}

To cite: Mitchell W, Bhatia R, Zebardast N. Retrospective cross-sectional analysis of the changes in marijuana use in the USA, 2005-2018. BMJ Open 2020;10:e037905. doi:10.1136/ bmjopen-2020-037905

- Prepublication history for this paper is available online. To view these files, please visit the journal online (http://dx.doi org/10.1136/bmjopen-2020037905).

Received 21 February 2020 Revised 19 June 2020 Accepted 22 June 2020

Check for updates

(C) Author(s) (or their employer(s)) 2020. Re-use permitted under CC BY-NC. No commercial re-use. See rights and permissions. Published by BMJ.

${ }^{1}$ Harvard School of Public Health, Harvard University,

Cambridge, Massachusetts, USA

${ }^{2}$ Department of Internal

Medicine, Beth Israel Deaconess Medical Center, Boston,

Massachusetts, USA

${ }^{3}$ Department of Ophthalmology,

Massachusetts Eye and

Ear Infirmary, Boston,

Massachusetts, USA

${ }^{4}$ Department of Ophthalmology, Harvard Medical School, Boston, Massachusetts, USA

Correspondence to Dr William Mitchell; william.greig.mitchell@gmail. com

\section{ABSTRACT}

Objectives Understanding trends of marijuana use in the USA throughout a period of particularly high adoption of marijuana-legalisation, and understanding demographics most at risk of use, is important in evolving healthcare policy and intervention. This study analyses the demographic-specific changes in the prevalence of marijuana use in the USA between 2005 and 2018.

Design, setting and participants A 14-year retrospective cross-sectional analysis of the National Health and Nutrition Examination Survey database, a publicly available biennially collected national survey, weighted to represent the entire US population. A total of 35212 adults between 18 and 69 years old participated in the seven-cycles of surveys analysed (2005-2018).

Primary outcome measured Lifetime use, first use before 18 years old, and past-year use of marijuana. Results The majority of adults reported ever using marijuana. While the overall prevalence of lifetime marijuana use remained stable ( $p=0.53)$, past-year use increased significantly between 2005 and $2018(p<0.001)$ with highest rate of past-year use among younger age groups $(p<0.001)$, males $(p<0.001)$ and those with income below poverty level $(p<0.001)$. Past-year use was the most common among non-Hispanic blacks, and less common among Hispanic/Mexican populations $(p<0.002)$. Trends in past-year use increased among all age categories, males/ females, all ethnicities, those with high school education/ above, and those at all income levels $(p<0.01$ for all). Conclusions While lifetime marijuana use remained stable, past-year use significantly increased between 2005 and 2018. While past-year use remained the most common in younger age groups, males, non-Hispanic blacks and those with lower income; increasing trends in past-year use were significant for all age, sex, race and income categories, and for those with high school education/above. With high adoption of marijuanalegalisation laws during this period, our results suggest an associated increase in past-year marijuana use.

An accurate understanding of those most at risk can help to inform decisions of healthcare policy-makers and professionals, and facilitate a safe transition of changing marijuana legalisation and use in the USA.

\section{INTRODUCTION}

While remaining illegal at the federal level in the USA, marijuana is now legal for recreational use by adults over the age of 21 in 11

\section{Strengths and limitations of this study}

This is the most recent study of trends of marijuana use in the USA, during a period of particularly high rates of adoption of marijuana legalisation laws.

- The National Health and Nutrition Examination Survey (NHANES) database is a publicly available and nationwide database. The NHANES database is weighted (standardised), to accurately represent the entire population of the United States.

- The NHANES database is self-reported, and limited by reporter bias.

- Missing data were primarily from participants who were older and female, potentially underestimating the true prevalence of marijuana use among this demographic.

- State-based legalisation information and use among adolescents less than 18 years old was not available, and could not be accurately correlated with changing trends of marijuana use.

states, and for medical use in 33 states. ${ }^{12}$ With particularly high adoption rates of medical marijuana legalisation between 2007 and $2016,{ }^{3}$ and increasing social acceptability of marijuana use, ${ }^{4-6}$ describing trends in use among different demographics in the USA is important in understanding which populations might be most affected by changing laws.

Prior studies have described increases in both marijuana use and misuse trends since medical marijuana legalisation ${ }^{48}$ in marijuana users both domestically and overseas. ${ }^{9}$ However, some studies have shown no changes to trends of past-year use since legalisation, ${ }^{1011}$ and others have shown only increases in marijuana misuse. ${ }^{11} \mathrm{~A}$ recent analysis even described a significant decrease in marijuana misuse disorder since legalisation. ${ }^{12}$ There have also been inconsistent reports of the demographics of those most affected by changing medical and recreational marijuana legalisation; some studies describing increasing trends across all gender, age and ethnic demographics, ${ }^{7}$ some showing 
trend changes particularly for young, black and Hispanic men, ${ }^{11}$ and others showing changes particularly among older individuals. ${ }^{4} 613$ Importantly, changing trends in medical and non-medical marijuana use do not appear to be restricted only to states with changing marijuana laws, ${ }^{14}$ despite being higher in states where laws have been passed. $^{7}$ An understanding of both the social and the economic cost-effectiveness of legalising marijuana, ${ }^{15} 16$ coupled with an understanding of trends of changing use, may be useful for those working in public health, public policy and healthcare, responsible for policy intervention or caring for populations most affected by marijuana use.

The current paper uses data from the US National Health and Nutrition Examination Survey (NHANES), a nationally representative sample of US adults, to examine the most recent 12 years trends in marijuana use in the USA. Additionally, we examine sociodemographic factors associated with marijuana use. We explore recent literature regarding the cost-effectiveness of medical and social marijuana legalisation, adding to the current body of literature important for those in policy or caring for those most affected.

\section{METHODS}

The NHANES is an ongoing biennial cross-sectional survey representing a non-institutionalised civilian US population, performed by the National Centre for Health Statistics (NCHS) and Centers for Disease Control and Prevention. NHANES has been a continuous survey programme providing health statistics for the US since 1999, examining a nationally representative sample of about 5000 people each year, located in counties across the USA. Study teams consisting of multilingual physicians, medical and health technicians, and dietary health interviewers conduct interviews and perform examinations, and information collected is intended to be used to determine the prevalence of major diseases and risk factors for diseases, and for health promotion and disease prevention; making NHANES an ideal data source to describe marijuana use trends in a nationally representative population. The sample for the survey is selected to represent the US population of all ages. To produce reliable statistics, NHANES oversamples persons 60 and older, African Americans and Hispanics. ${ }^{17}$

In the present study, seven 2-year cycles of NHANES survey data between 2005 and 2018 (inclusive) have been retrospectively analysed for baseline demographic information, and drug use questionnaire data. A total of 35212 adults (US citizens) between 18 and 69 years old participated in the seven cycles of surveys analysed. Of these, $32.9 \%$ had missing marijuana survey data. Those with missing data were significantly more likely to be older $(\mathrm{p}<0.001)$, female $(\mathrm{p}<0.001)$ and have less than high school education $(\mathrm{p}<0.001)$. Missing data were handled by pairwise deletion to optimise data available for analysis. Participants undergo a home interview, and a comprehensive physical examination in a mobile examination centre (MEC). Written informed consent obtained from all participants.

Demographics data including age, gender, race/ ethnicity, education and income were collected during the home interview. The drug use questionnaire was conducted in the MEC, and aimed to assess lifetime, past year and current usage of marijuana. Questions are selfadministered using the Audio Computer-Assisted SelfInterview (ACASI) system. The ACASI was conducted in English, Spanish, Korean, Vietnamese or Chinese (Mandarin and Cantonese). Participants reported lifetime use, age at first use and use within the past year of marijuana.

Given the NHANES complex probability sampling design, 2-year interview weights computed by the NCHS were used to calculate prevalence estimates and 95\% CIs (Taylor linearisation), age standardised to the 2000 US Census population as recommended by the NCHS. Differences in prevalence estimates were compared using $\chi^{2}$ tests. Univariate regression models were used to test for significant linear trends while multivariable regression models were used to determine characteristics associated with recent marijuana use. Results at the $p<0.05$ level considered statistically significant. Statistical analysis was performed using STATA V.15.0 (StataCorp).

\section{Patient and public involvement}

Patients or the public were not involved in the development of the research question or study design, in the measurement of the outcomes, or in the dissemination of results for the present study.

\section{RESULTS}

Overall, $53.5 \%$ (95\% CI $52.8 \%$ to $54.1 \%$ ) of the US adult population reported ever using marijuana between 2005 and 2018. The prevalence of lifetime marijuana use, and first use before the age of 18, remained stable between 2005 and 2018 ( $\mathrm{p}=0.53$ and $\mathrm{p}=0.68$, respectively) (table 1). Overall $22.6 \%$ (95\% CI $22.1 \%$ to $23.1 \%$ ) of US adults reported using marijuana within the last year. The weighted prevalence of past-year marijuana use increased significantly during the study period from $19.1 \%$ (95\% CI $15.3 \%$ to $23.7 \%$ ) in $2005 / 2006$ to $29.1 \%$ (95\% CI $26.0 \%$ to $32.5 \%)(\mathrm{p}=0.001)$ in $2017 / 2018$.

The prevalence of past-year marijuana use was higher among younger age groups $(p<0.001)$, males $(p<0.05)$, and those with income below poverty level $(p<0.05)$ (table 2). Past-year marijuana use was more common among non-Hispanic blacks, and less common among Hispanic/Mexicans $(\mathrm{p}<0.002$ (excluding 2011/2012 and 2017/2018)). Between 2005 and 2018, the prevalence of past-year marijuana use increased among all age categories $(p<0.001)$, males and females $(p<0.001)$, all racial categories $(p<0.01$ for all groups), those with high school education or above $(\mathrm{p}<0.001$ for both) and those at all levels of income $(\mathrm{p}<0.01)$. 


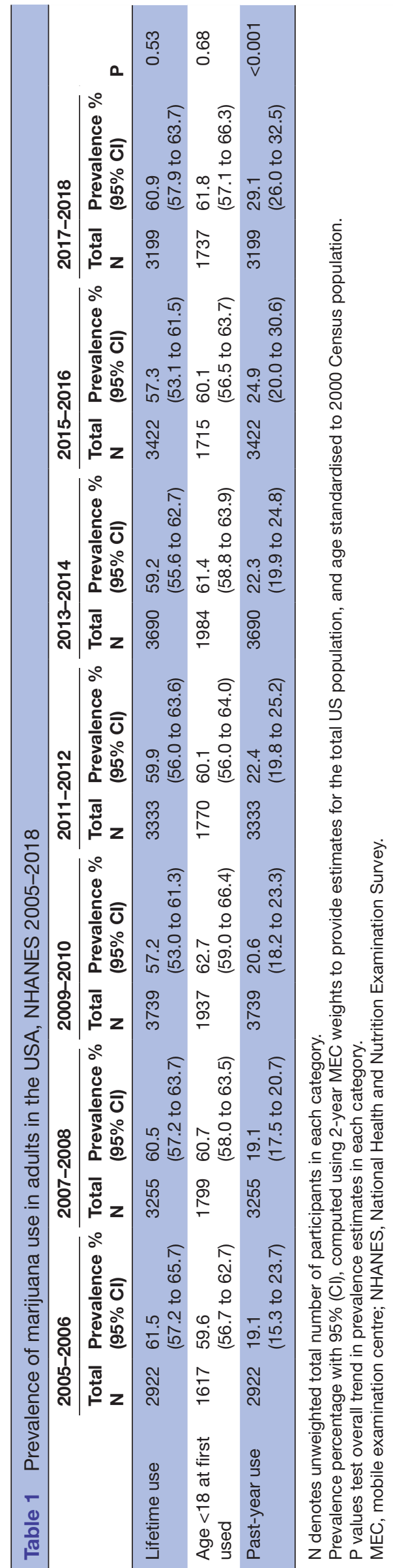

Multivariate logistic regression analysis demonstrated higher odds of past-year marijuana use among younger age groups $(\mathrm{p}<0.001)$, males $(\mathrm{p}<0.001)$, non-Hispanic blacks $(\mathrm{p}<0.001)$ and those with income below the poverty level ( $p<0.001$ for both) (table 3). Past-year use was less likely among older individuals $(\mathrm{p}<0.001)$, and Hispanic and Mexican Americans $(\mathrm{p}<0.001)$ and those with higher levels of education $(\mathrm{p}=0.003)$ (table 3$)$.

\section{DISCUSSION}

The current study presents the most recent changes in marijuana use in the USA during a period of particularly high legalisation. It finds that while lifetime marijuana use, and first use before the age of 18 , has remained stable, the overall prevalence of past-year marijuana use has significantly increased over the 14-year period. While past-year use was still more common among younger age groups, males, non-Hispanic blacks and those with lower income, significant trends of increasing past-year use were seen in all age categories, males and females, all racial categories, highly educated populations and all income levels. Age-specific marijuana use trend in response to legalisation laws has been studied elsewhere; but with inconsistent findings. There has been growing consensus that increasing recent-use of marijuana is seen among late to middle-aged adults after legalisation ${ }^{613}$; a recent study by Salas-Wright and colleagues showing trends of increasing past-year use among late to middle-aged adults in the USA between 2002 and 2014, ${ }^{5}$ findings that are supported by the present study. Whether this pattern of recent use among older populations is associated with increasing marijuana-use for medicinal purposes (seen most prominently among older, white, male and highincome populations in the USA), ${ }^{14}$ is unclear, and such data were not available for analysis in the present study. However, there has been less consensus about recent-use trends among adolescent populations. While a comprehensive study by Harpin et al described no change in adolescent-use after legalisation ${ }^{10}$ (further supported by more recent findings ${ }^{6}$ ), a 2019 review by Bae and Kerr described increasing recent-use among adolescents in the USA after legalisation. ${ }^{8}$ Contrastingly, a 2016 US study by Grucza et al describes that past-year marijuana use actually decreased among adolescents, during the highest periods of legalisation. ${ }^{12}$ Information about marijuana-use trends in adolescents less than 18 years old was not publicly available on NHANES for the present study, but it has been noted that over the 14-year study period, there has been no significant change in reported first use before the age of 18 (table 1).

Our findings of younger, male, non-Hispanic black and lower-income populations being most likely to use marijuana overall, are also consistent with previous findings not aforementioned. ${ }^{4}$ Native American populations, those living in urban areas, and those living in western states, have also been shown to be more likely to have recently used marijuana; but this information was not 


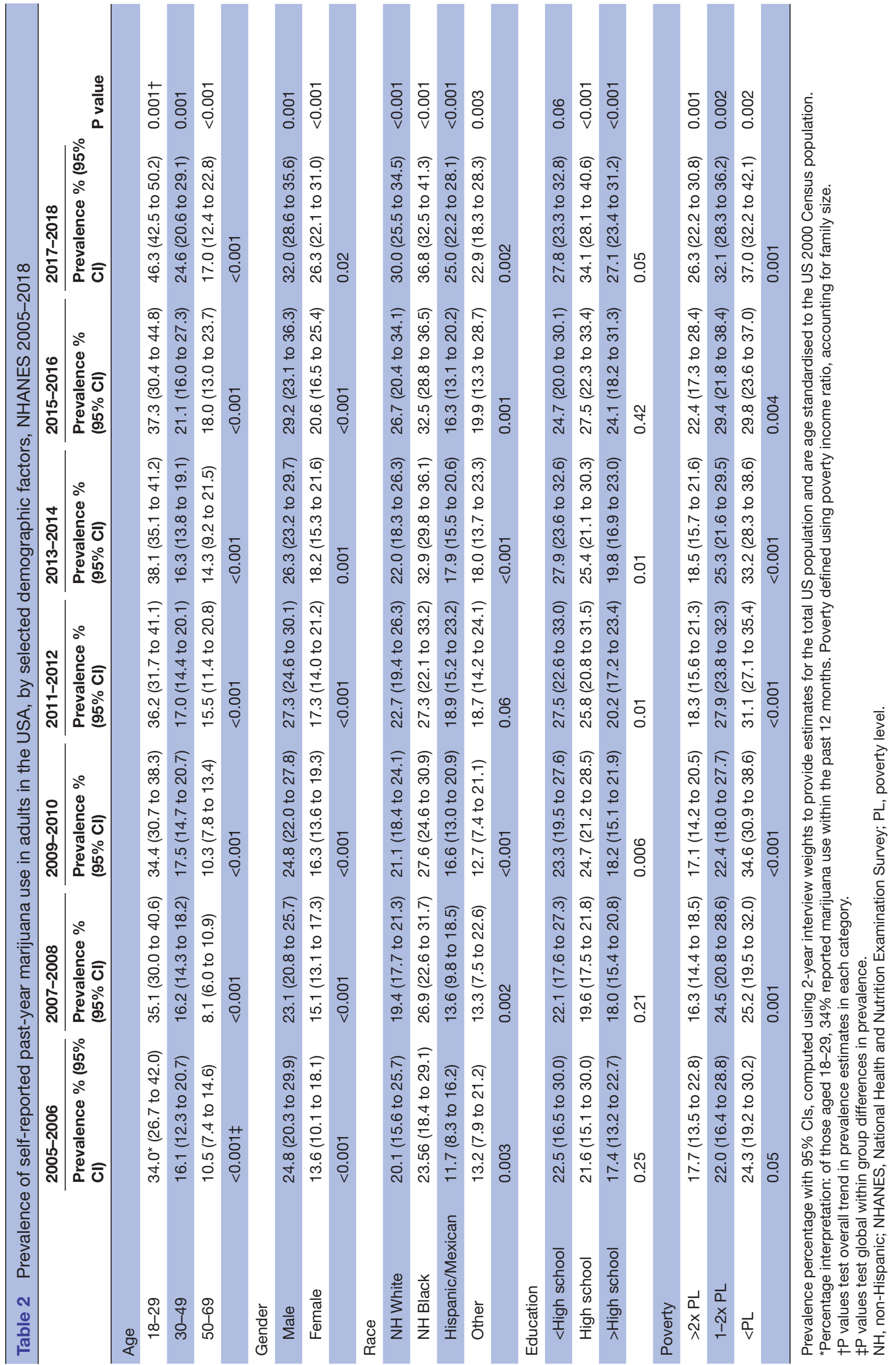


Table 3 Adjusted odds of past-year marijuana use in adults in the USA, NHANES 2005-2018

\begin{tabular}{|c|c|c|}
\hline Demographic variable & $\begin{array}{l}\text { Past-year } \\
\text { marijuana use } \\
\text { OR }(95 \% \mathrm{Cl})\end{array}$ & $P$ value \\
\hline \multicolumn{3}{|l|}{ Age of participants } \\
\hline 18-29 & 1.0 (reference) & \\
\hline $30-49$ & 0.39 (0.36 to 0.43$)$ & $<0.001$ \\
\hline $50-69$ & 0.26 (0.22 to 0.30$)$ & $<0.001$ \\
\hline \multicolumn{3}{|l|}{ Gender } \\
\hline Female & 1.0 (reference) & \\
\hline Male & 1.67 (1.55 to 1.81$)$ & $<0.001$ \\
\hline \multicolumn{3}{|l|}{ Race } \\
\hline Non-Hispanic white & 1.0 (reference) & \\
\hline Non-Hispanic black & 1.23 (1.09 to 1.39$)$ & 0.001 \\
\hline Hispanic/Mexican & 0.51 (0.44 to 0.58$)$ & $<0.001$ \\
\hline Other & 0.63 (0.54 to 0.73$)$ & $<0.001$ \\
\hline \multicolumn{3}{|l|}{ Education } \\
\hline$<$ High school & 1.0 (reference) & \\
\hline High school & 0.95 (0.81 to 1.12$)$ & 0.58 \\
\hline$>$ High school & 0.82 (0.73 to 0.93$)$ & 0.003 \\
\hline \multicolumn{3}{|l|}{ Poverty } \\
\hline$>2 x$ poverty level & 1.0 (reference) & \\
\hline $1-2 x$ poverty level & 1.41 (1.24 to 1.59$)$ & $<0.001$ \\
\hline$<$ Poverty level & 1.69 (1.49 to 1.92$)$ & $<0.001$ \\
\hline Year of survey & 1.10 (1.05 to 1.14$)$ & $<0.001$ \\
\hline
\end{tabular}

OR with 95\% Cls computed using 12-year interview weights to provide estimates for the total US population and are age standardised to the US 2000 Census population.

Poverty defined using poverty income ratio, which accounts for family size.

Year covariate modelled as a continuous variable.

NHANES, National Health and Nutrition Examination Survey.

available on NHANES in sufficient detail, for the present analyses.

In addition to demographic risk factors indicating potential marijuana use, an understanding of other risk factors is important for those involved in fields of public policy and healthcare. While age and gender remain somewhat inconsistently described risk factors, tobacco smoking is a demonstrated risk factor for marijuana use. Though not analysed in the present study, a recent study demonstrated that current smokers have almost 6 $\mathrm{x}$ increased odds of recent marijuana use compared with non-smokers, ${ }^{18}$ outlining another subpopulation particularly at risk. Another group at risk of increasing marijuana use are non-medical users of prescription drugs (NMUPD). A recent study by Karjalainen et al demonstrated significantly increasing trends of illicit drug use among NMUPD (92\% of whom had used cannabis in the last year), that could not otherwise be explained by age or gender. ${ }^{19}$
Important to consider in the context of the present findings is that marijuana-use trends may not to be restricted only to states with marijuana legalisation. In 2017, Hasin et al demonstrated significantly increased marijuana use both in states with and without marijuana legalisation laws, ${ }^{47}$ although fractionally higher in states where marijuana was legalised. However, a recent analysis by Han et al demonstrated a significantly higher trend of increasing medical-marijuana use in states without legalisation (adjusted OR, AOR 1.4, 95\% CI 1.05 to 1.90), compared with states with legalisation (AOR 1.3, 95\% CI 1.03 to 1.61$) ;{ }^{14}$ underlining the fact that evolving legalisation laws are also of relevance to states where recreational and medical marijuana use remains illegal.

Exploring the economic and societal cost-effectiveness of marijuana legalisation is also important for those involved in healthcare policy and decision making. Marijuana legalisation was posited to lower price, increase availability and thereby increase marijuana use, ${ }^{6}$ with early fears that profit motive would take precedence over public health issues. ${ }^{20}{ }^{21}$ The retail price of marijuana on the legal cannabis market had sharply fallen by almost 70\%, just 3 years after legalisation in Washington state. ${ }^{22}{ }^{23}$ Some reports described an initial increase in self-reported street prices of marijuana in response to legalisation as demand increased, by up to $36 \%,{ }^{24}$ with limited price change thereafter. However, similarly to results aforementioned, medical legalisation appears to have affected only adult marijuana use, with minimal significant changes to adolescent use. ${ }^{13}$ While studies of the effect of recreational marijuana legalisation on its use are still emerging, there appears to be no/minimal effect on adolescent or college marijuana use. ${ }^{13}$ The passage of legalisation laws also offers an important social justice benefit ${ }^{25}$; by removing mechanisms for unfair, damaging disparities in law enforcement. ${ }^{26}$ While more permissive marijuana laws may appeal to social justice aims (reducing racial disparity in law enforcement), and increase revenue to state and local government through taxation, ${ }^{6}$ the public health trade-offs and overall costs of use-related adverse physical and psychosocial consequences ${ }^{27}$ in response to changing laws remains difficult to accurately describe. ${ }^{6}$

\section{Strengths and limitations}

Strengths of our study include the size and heterogeneity of our population, the timespan, and the age standardisation of the NHANES data. Limitations to our study include reliance on self-reported data and reporter-bias, which may not have affected all demographics equally. Missing data were primarily from participants who were older and female, potentially underestimating the true prevalence of marijuana use among this demographic. Our dataset did not include youth aged 12-17 years old, a potentially at-risk population, nor include analysis of other risk factors associated with marijuana use (use of tobacco or NMUPD). Certain ethnicity data (ie, Native American identifiers) and geographical data (ie, whether 
collected from states with or without legalisation) were not available for analysis, nor was detail of marijuana use for medicinal or recreational purposes.

\section{CONCLUSION}

Our primary two findings describing characteristics of those most at risk of using marijuana, and those where trends of use have most significantly increased, adds to the current body of literature and understanding of marijuana trends in the USA. Given ongoing changes to marijuana legalisation in the USA, with the evolving public perception of marijuana safety and accessibility, an accurate understanding of which populations are most likely to be implicated, which additional predictive tools can identify those most at risk, and a balanced presentation of healthcare, social and economic costs of legalisation, is warranted. Identification of these factors can help to inform the decisions of healthcare policy makers and professionals, and facilitate a safe transition of evolving marijuana legalisation and use in the USA.

Contributors WM: analysis plan, data analysis and interpretation, manuscript composition and editing, submission, correspondence. RB: analysis plan, data interpretation, manuscript editing. NZ: analysis plan, data extraction, analysis and interpretation, manuscript composition.

Funding The authors have not declared a specific grant for this research from any funding agency in the public, commercial or not-for-profit sectors.

Patient and public involvement Patients and/or the public were not involved in the design, or conduct, or reporting, or dissemination plans of this research.

Patient consent for publication Not required.

Ethics approval The 2005-2018 NHANES protocol was approved by the National Centre for Health Statistics research ethics review board.

Provenance and peer review Not commissioned; externally peer reviewed.

Data availability statement Data are available in a public, open access repository. All data relevant to the study are included in the article or uploaded as online supplementary information. Data are publicly available at https://wwwn.cdc.gov/ nchs/nhanes/Default.aspx.

Open access This is an open access article distributed in accordance with the Creative Commons Attribution Non Commercial (CC BY-NC 4.0) license, which permits others to distribute, remix, adapt, build upon this work non-commercially, and license their derivative works on different terms, provided the original work is properly cited, appropriate credit is given, any changes made indicated, and the use is non-commercial. See: http://creativecommons.org/licenses/by-nc/4.0/.

ORCID iD

William Mitchell http://orcid.org/0000-0002-0112-5492

\section{REFERENCES}

1 Cohn AM, Johnson AL, Rose SW, et al. Support for marijuana Legalization and predictors of intentions to use marijuana more often in response to Legalization among U.S. young adults. Subst Use Misuse 2017;52:203-13.

2 Berke J, Gould S. Legal marijuana just went on sale in Illinois, here are all the states where cannabis is legal business insider, 2020. Available: https://www.businessinsider.com/legal-marijuana-states2018-1

3 National Conference of State Legislatures. State medical marijuana laws, 2019. Available: http://www.ncsl.org/research/health/statemedical-marijuana-laws.aspx
4 Hasin DS, Saha TD, Kerridge BT, et al. Prevalence of marijuana use disorders in the United States between 2001-2002 and 2012-2013. JAMA Psychiatry 2015;72:1235-42.

5 Salas-Wright C, Vaughn M, Cummings-Vaughn L, et al. Trends and correlates of marijuana use among late middle-aged and older adults in the United States, 2002-2014. Drug Alcohol Depend 2017;1:97-106.

6 Carliner H, Brown QL, Sarvet AL, et al. Cannabis use, attitudes, and legal status in the U.S: a review. Prev Med 2017;104:13-23.

7 Hasin DS, Sarvet AL, Cerdá M, et al. Us adult illicit cannabis use, cannabis use disorder, and medical marijuana laws: 1991-1992 to 2012-2013. JAMA Psychiatry 2017;74:579-88.

$8 \mathrm{Bae} \mathrm{H}$, Kerr D. Marijuana use trends among college students in states with and without Legalization of recreational use: initial and longer-term changes from 2008 to 2018. addiction. Research Report 2019.

9 Karjalainen K, Savonen J, Hakkarainen P. Drug use and drug attitudes among finns - drug related population surveys in Finland 1992-2014. Helsinki, Finland: National Institute for Health and Welfare, 2016.

10 Harpin SB, Brooks-Russell A, Ma M, et al. Adolescent marijuana use and perceived ease of access before and after recreational marijuana implementation in Colorado. Subst Use Misuse 2018;53:451-6.

11 Compton W, Grant B, Colliver J, et al. Prevalence of marijuana use disorders in the United States 1992-1992 and 2001-2002. JAMA Network 2004;291:2114-21.

12 Grucza RA, Agrawal A, Krauss MJ, et al. Declining prevalence of marijuana use disorders among adolescents in the United States, 2002 to 2013. J Am Acad Child Adolesc Psychiatry 2016;55:487-94.

13 Smart R, Pacula RL. Early evidence of the impact of cannabis Legalization on cannabis use, cannabis use disorder, and the use of other substances: findings from state policy evaluations. Am J Drug Alcohol Abuse 2019;45:644-63.

14 Han B, Compton WM, Blanco C, et al. Trends in and correlates of medical marijuana use among adults in the United States. Drug Alcohol Depend 2018;186:120-9.

15 Shanahan M, Ritter A. Cost benefit analysis of two policy options for cannabis: status quo and legalisation. PLoS One 2014;9:e95569.

16 Tyree GA, Sarkar R, Bellows BK, et al. A cost-effectiveness model for adjunctive smoked cannabis in the treatment of chronic neuropathic pain. Cannabis Cannabinoid Res 2019;4:62-72.

17 Center for Disease Control and Prevention. National health and nutrition examination survey national center for health statistics, 2017. Available: https://www.cdc.gov/nchs/nhanes/about_nhanes. $\mathrm{htm}$

18 Moeller SJ, Fink DS, Gbedemah M, et al. Trends in illicit drug use among smokers and nonsmokers in the United States, 2002-2014. J Clin Psychiatry 2018;79.

19 Karjalainen K, Lintonen T, Hakkarainen P. Illicit drug use is increasing among non-medical users of prescription drugs-Results from population-based surveys 2002-2014. Drug Alcohol Depend 2017;178:430-4.

20 Pacula RL, Kilmer B, Wagenaar AC, et al. Developing public health regulations for marijuana: lessons from alcohol and tobacco. Am J Public Health 2014;104:1021-8.

21 Room R. Legalizing a market for cannabis for pleasure: Colorado, Washington, Uruguay and beyond. Addiction 2014;109:345-51.

22 Humphreys K. How legalization caused the price of marijuana to collapse Washington post, 2017. Available: https://www. washingtonpost.com/news/wonk/wp/2017/09/05/how-legalizationcaused-the-price-of-marijuana-to-collapse/

23 Smart R, Caulkins JP, Kilmer B, et al. Variation in cannabis potency and prices in a newly legal market: evidence from 30 million cannabis sales in Washington state. Addiction 2017;112:2167-77.

24 Hunt P, Pacula RL. Early impacts of marijuana legalization: an evaluation of prices in Colorado and Washington. J Prim Prev 2017;38:221-48.

25 Jensen EL, Roussell A. Field observations of the developing legal recreational cannabis economy in Washington state. Int J Drug Policy 2016;33:96-101.

26 Golub A, Johnson BD, Dunlap E. The race/ethnicity disparity in misdemeanor marijuana arrests in New York City. Criminol Public Policy 2007;6:131-64.

27 Hall W. Alcohol and cannabis: comparing their adverse health effects and regulatory regimes. Int J Drug Policy 2017;42:57-62. 